\title{
A bus stop shelter evaluated from the user's perspective
}

\author{
Vera Helena Moro Bins Ely ${ }^{\mathrm{a}^{*}}$, Jonara Machado de Oliveira ${ }^{\mathrm{a}}$ and Louise Logsdon ${ }^{\mathrm{a}}$ \\ ${ }^{a}$ Pós Graduação em Arquitetura e Urbanismo, Centro Tecnológico, Universidade Federal de Santa Catarina, \\ Campus UFSC - Trindade, Caixa Postal 476, CEP 88040-900, Florianópolis, SC, Brazil.
}

\begin{abstract}
This study aims to evaluate the current bus stop shelter model used in Florianópolis, Brazil, through a functional analysis - focused in the relationship between the shelter, the users and their activities - and also to analyse users' perceptions. The methodology consisted of exploratory visits, anthropometric analysis, observation and interviews. The exploratory visit intended to survey the physical characteristics of the shelter (dimensions, materials, colors, displayed information) and its position on the sidewalk. The anthropometric analysis was made to verify whether the dimensions of the shelters were adequate to users' needs. The observation provided data for the analysis of users' behavior, which involved a biomechanical study of their postures, an ownership/occupancy analysis in terms of territoriality and studies about spatial requirements of interpersonal relations (proxemics). The interviews helped to analyze how the user perceives the quality of some of the main functions of the shelter: to provide physical and psychological comfort and to display information about the public transportation system. As a result, the overall conclusion is that shelters do not meet users' needs. Recommendations are provided in order to improve physical and psychological comfort and to display relevant information about the transportation system.
\end{abstract}

Keywords: ergonomics, environmental perception, anthropometry

\section{Introduction}

The public transportation system is responsible for the mobility of a large amount of the population. Waiting for public transport might be one of the most wearing situations for users. Some characteristics of bus shelters may improve or aggravate this experience.

Besides being an access to catch the buses, shelters should provide physical and psychological comfort. Bus shelters also allow their users to interact with other people, which may be considered a sociocultural function [1].

In order to provide physical comfort, bioclimatic and functional attributes are required. The bioclimatic attributes consist of weather protection and thermal comfort. The functional attributes consist of dimensions adequate to users' needs and enough space to seat or stand, while assuring the maintenance of a restful posture.

The psychological comfort is related to users' own safety perception, to a good visibility of the traffic so they can see the arrival of the buses, means for estimating waiting times, and the presence of elements that could reduce fatigue — such as comfortable seats, displayed information about the transportation system and also urban furniture (trash bins, public telephones and public gardens). The access to the bus from the shelter also influences the user's physical and psychological comfort; however, this attribute won't be considered in this study.

The socio-cultural function is about users' behavior, their interaction with other people (interpersonal relationships) and with the shelter (territoriality) [1].

Due to its importance in the transportation system, the bus stop shelter was chosen by Bins Ely [1] as the object of study for developing and validating a method called MEGA - Method of Attributes Grid.

Three types of shelter that existed in the city at the time of the study were selected and evaluated using MEGA and other two methods. The comparison of the three methods presented very similar results, that shelters were not adequate and not meeting users' needs.

\footnotetext{
*Corresponding author. E-mail: vera.binsely@gmail.com
} 
This research was published and broadcasted on television, radio and newspaper, reaching the public department responsible for designing shelters. A few years later, a new bus shelter was created by the same public department, and put all across the city.

This study aims to evaluate a current bus stop shelter using a functional analysis, focused on the following relationship: shelter $\times$ users $\times$ activities.

\section{Methods}

\subsection{Exploratory visit}

The exploratory visit aimed to survey the physical characteristics of the shelter (dimensions, materials, colors, displayed information) and its position on the sidewalk. The shelter was measured and photographed.

The attributes of environmental comfort (thermal, luminous and acoustic comfort) were not measured in a technical way. These attributes were evaluated through the analysis of users' perception.

\subsection{Anthropometric analysis}

This method was used to verify whether the dimensions of the shelter were adequate to users' needs. The analysis was based on 3D models, created on SketchUp ${ }^{\mathcal{O}}$ 7.1. People representing the Brazilian population (average height and 5-95, percentile men and women, [4] and children able to use the city transportation system - average height of a 10 years old child [5]) were modeled and compared to a 3D model of the shelter. 21 images were generated for analysis.-

\subsection{Observation}

The observation provided data for the analysis of user's behaviors, which involved a study of their postures [1] and an ownership /occupancy analysis in terms of territoriality [2] and proxemics [3]. To avoid interfering with the subjects, the observers positioned themselves at a place where they couldn't be seen [7].

Due to insufficient data concerning the quantity of users of a shelter of this kind, a random sample of sixty users was observed.

The following data was placed in a standardized spreadsheet: sex, estimated age range, waiting time, postures adopted, whether the user was alone or accompanied, distance between users and any activities carried out by them. Sequential photographs were taken to support subsequent analysis.

The observations were made on two afternoons of August, 2010. The weather was good, and the temperature was about $18^{\circ} / 20^{\circ}$ Celsius.

\subsubsection{Analysis of users' behavior}

The data registered in the observation forms (sex, age, postures adopted, activities carried out and waiting time) were correlated and organized in tables.

\subsubsection{Biomechanical analysis}

Postures adopted by users were photographed and compared to frequent harmful postures [1].

\subsubsection{Analysis of ownership/occupancy in terms of territoriality}

The analysis of territoriality was used to study the person's or groups' behavior related to ownership/occupancy of a place [2]. The photographs of the users' behavior were compared to the ones took on a previous research [1].

\subsubsection{Analysis of proxemics}

This analysis was used to study the distances between people during their interactions [3]. Distances between users (registered by sequential photographs) were analyzed and compared with a previous study [1].

\subsection{Interviews}

Interviews were used to analyze how users perceive the quality of some of the shelter's main functions: to provide physical and psychological comfort.

Interviews were carried out on another sample of 60 adult users, including 30 elderly. The interview was structured in a form consisting of 21 questions. The first two were open and had the objective of comparing the attributes of a current shelter with the desirable characteristics of an ideal one, using the Constellation of Attributes technique [6].

The remaining questions included pre-defined multiple choice answers and their purpose was to gather information about the users' profiles (age, sex, whether they were tourists or residents), waiting time perception and users' satisfaction regarding several aspects of the shelter (dimensions, weather protection, environmental comfort, comfort of the seat, traffic visibility from inside the shelter, shelter appearance and available information about the transportation system). 
The average time spent on interviews was $4 \mathrm{mi}$ nutes. They were carried out in the morning, afternoon and evening for three days in August, 2010. The weather was good, and the temperature was about $18^{\circ} / 20^{\circ}$ Celsius.

The Excel 2007 was used to correlate the obtained data. The answers were grouped in different categories : adults, elderly, men, women, residents and tourists. Tables and graphs were created and the obtained information was analyzed in a qualitative and quantitative way.

\section{Results}

\subsection{The object of study}

The analyzed shelter is located in a residential neighbourhood, in front of a small shopping mall, near a university campus and next to the main church and plaza.

The shelter is made of metallic structure, glass weather protection and translucent roof. There is a central bench in the rear of the shelter, and free space around it for users who wait in a standing position. The bench is made of metallic tubes, two for the seat and one for the back, and it was designed for the use of five or six people.

The shelter was built directly on the sidewalk, and its floor has the same declivity of the street. The shelter is situated near the buildings that are behind it and is away from the curb, so pedestrians can walk in front of the shelter (Figure 1).

The following information is displayed outside the shelter: name of the street, shelter's identification number and city hall logo.

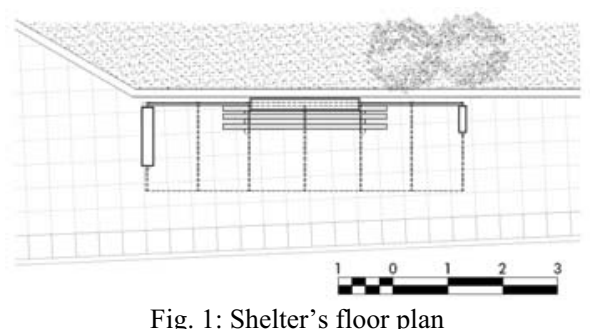

About the elements responsible for providing physical comfort, it was observed that:

- The weather protection ends far away from the floor, so people who stand next to it may get wet in rainy days;
- The design of the bench is inappropriate. Its material gets cold in the winter and its shape does not hold the body correctly;

- Due to sidewalk's declivity, the shelter floor is oblique in relation to the bench (Figure 2). The difference between the floor and the seat makes the bench inappropriate for some users.

In what regards the elements responsible for providing psychological comfort, the study highlighted the following:

- Due to the shelter's position on the sidewalk, the visibility from inside the shelter is obstructed by pedestrians;

- The shelter's dimensions are inadequate on peak hours. Personal space is reduced, and seated users can't see the bus coming;

- The translucent protection from weather makes the shelter look lighter and improves visibility;

- The absence of city maps and displayed information about the transportation system may upset some users.

\subsection{Anthropometrics}

The bench is uncomfortable and its shape does not support correctly the lumbar region (and the buttocks). Its dimensions are inadequate for most users. They are only adequate for 95 percentile men (Height $184,10 \mathrm{~cm})$. The bench is not ideal even for these users. Due to the sidewalk's declivity, at one of its extremities (Figure 2, Point A), the distance between the floor and the seat is shorter than the ideal, making the angle of the knees sharper than recommended. The distance between the floor and the seat is larger than the ideal at Point B for the other men_(Figure 2), and these users can't comfortably put their feet on the floor.

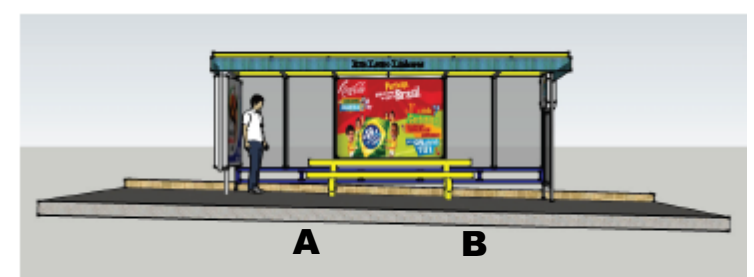

Fig. 2: The declivity of the sidewalk is visible in this shelter's sketch. The distance between the floor and the seat is smaller at point $\mathrm{A}$ than at point $\mathrm{B}$.

Medium stature women just seat comfortably on one extremity of the bench (Figure 2, Point A). They can't comfortably put their feet on the floor while 
seated on the remaining extension of the bench. It is completely inadequate for 5 percentile women (Height $151,80 \mathrm{~cm}$ ) and 10 year old children (Height $140,00 \mathrm{~cm})$. These users can't simply put their feet on the floor while seated. This posture may cause pain in the back of the legs, and also in the knees and feet.

\subsection{Users' behavior}

By comparing age groups, adopted postures and waiting time (Table 1), the study concluded that:

- Most of elderly wanted to wait in a seated position $(75 \%)$;

- Adults were divided between those who waited in a seated position and those who waited in a standing one;

- The average waiting time was six minutes for adults and nine minutes for elderly. It is possible to infer that elderly spend more time at the shelter because they try to get early at the bus stop .

\begin{tabular}{lccccc}
\multicolumn{6}{c}{ Table 1: Users, postures and waiting time } \\
\hline & $\begin{array}{c}\text { Users } \\
\%\end{array}$ & $\begin{array}{c}\text { Waiting } \\
\text { time }\end{array}$ & $\begin{array}{c}\text { Standing } \\
(\%)\end{array}$ & $\begin{array}{c}\text { Seated } \\
(\%)\end{array}$ & $\begin{array}{c}\text { Switching } \\
(\%)\end{array}$ \\
\hline Elderly & 9,33 & $9^{\prime} 52^{\prime}$, & 25,00 & 75,00 & 0,00 \\
Adults & 90,67 & $6 ' 28^{\prime}$ & 43,33 & 40,00 & 16,67 \\
\hline
\end{tabular}

From the comparison between users' adopted postures and waiting time (Table 2) it can be said that:

- 34\% of users who waited standing supported their bodies on the lateral parts of the shelter, probably looking for more comfort;

- $35 \%$ of the users who waited in a seated position inclined their bodies to look at the arrival of buses.

The more time people waited, the more they alternated their postures between standing and seated. $80 \%$ of these users supported their bodies on the lateral walls of the shelter, or inclined themselves, to be able to see the arrival of buses. It is possible to suppose that users switch their positions to look at the traffic and to feel more comfortable.

\begin{tabular}{lccc}
\multicolumn{4}{c}{ Table 2: Users' postures and waiting time } \\
\hline & $\begin{array}{c}\text { Users } \\
\%\end{array}$ & $\begin{array}{c}\text { Medium } \\
\text { waiting time }\end{array}$ & $\begin{array}{c}\text { Support/ } \\
\text { Incline body }\end{array}$ \\
\hline Standing & 40,31 & $5^{\prime} 45^{\prime \prime}$ & 34,09 \\
Seating & 41,99 & 6'27' & 35,00 \\
Switching & 17,69 & 8'07' & 80,00 \\
\hline
\end{tabular}

From the comparison between age groups and their position in relation to -the shelter (Table 3 ), it was observed that:

- More than half of the users waited in the shelter;
- All elderly waited in the shelter;

$-20 \%$ switched between in and out of the shelter;

$-25 \%$ of the users waited outside of the shelter.

Considering that the observations were made in good weather conditions, it is possible to infer that users move in and out of the shelter so they are able to see the arrival of buses and to keep a personal distance that best suits their needs. It is possible to suppose that on rainy days the shelter's size would be insufficient.

\begin{tabular}{lccc}
\multicolumn{4}{c}{ Table 3: Users' positions related to the shelter } \\
& In & Out & Switching \\
& $(\%)$ & $(\%)$ & $(\%)$ \\
\hline Men & 20,00 & 2,80 & 11,42 \\
Women & 34,28 & 22,85 & 8,50 \\
Young & 47,05 & 41,17 & 11,76 \\
Adult & 56,25 & 12,50 & 31,25 \\
Elderly & 100,00 & - & - \\
Total & 54,28 & 25,71 & 20,00 \\
\hline
\end{tabular}

From the analysis of the activities carried out by users while waiting for the bus (Table 4), the following can be concluded:

- The most frequent activity was conversation: $39 \%$ of the users talked with friends or strangers while waiting;

- $16 \%$ of the users asked for information about the transportation system;

- $16 \%$ of the users used their cell phones;

$-15 \%$ of the users separated the money for the ticket ;

- Reading was the least frequent activity, probably because it requires higher levels of concentration...

It is possible to infer that users prefer activities that don't require much concentration and that allow a better visibility of the traffic.

\begin{tabular}{lc} 
Table 4: Activities performed by users while waiting & \\
\hline Activity & $\%$ Users \\
\hline Using the cell phone & 16,00 \\
Separating the money & 15,92 \\
Talking with strangers & 10,08 \\
Talking with friends & 29,03 \\
Asking for information & 16,05 \\
Reading & 2,90 \\
Listening to music (using headphones) & 8,82 \\
\hline
\end{tabular}

\subsubsection{Biomechanical Analysis}

The following postures were identified: standard seated, inclined seated, reclined seated, standard standing and supported standing.

When the user waits on the standard seated position (Figures 3 and 4), the upper part of the body is 
erect while the thighs remain in a horizontal position, making a $90^{\circ}$ angle. Keeping this posture for a long time may overload the pelvis bones, which may cause postural, vascular and also respiratory diseases [1]. It would be possible to avoid these problems if the seat and the back of the bench were more comfortable and appropriate for being used by different people.

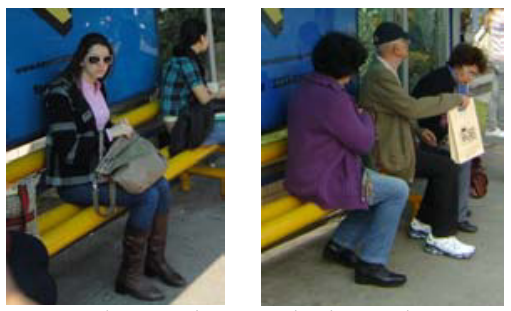

Fig. 3 and 4: Standard seated

Users usually seat inclined so they can look at the buses (Figure 5). This posture causes mechanical disadvantages to dorsal musculature, aggravated by dorsal kyphosis and frontal projection together with lateral movements of the head. A great pressure is put on intervertebral discs [1]. Users could avoid to adopt these postures if visibility from inside the shelter was unobstructed.

When seated reclined (Figure 6), the user supports the head on the back of the shelter and moves the hip to the extreme side of the seat, making an obtuse angle between body and thighs. This posture overloads the vertebral column and the neck [1]. Users could avoid this posture if the bench was more comfortable.

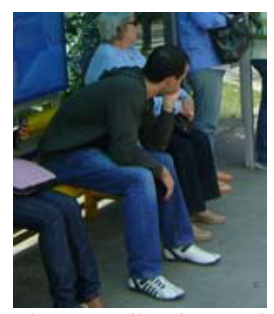

Fig. 5: Inclined Seated

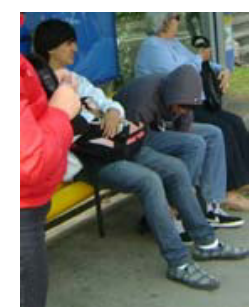

Fig. 6: Reclined Seated
When the user waits on a standard standing posture (Figure 7), the body can keep a good balance. By keeping this posture, the user doesn't overload spinal ligaments and muscles, because the gravity force is annulled by the straight position of the spine and the other bones [1]. However, this is a fatiguing posture because it demands a great static effort of the musculature.

When the user waits in a supported standing posture (Figure 8), one of the shoulders supports part of the weight of the body, overloading its musculature. The user switches postures, supporting different parts of the body, looking for more balance.

Different types of seats (like a high bench that supports the hips) and an increase of their number could reduce discomfort while waiting.

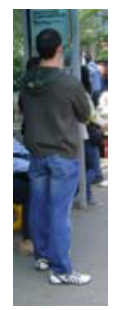

Fig. 7: Standard Standing

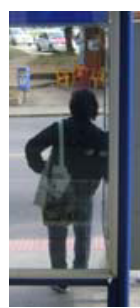

Fig. 8: Supported Standing

\subsubsection{Territoriality and ownership/occupancy}

Three types of space related to ownership/occupancy were identified: delimitation, exploration and obstruction.

- Delimitation: users put next to them personal items, such as bags and backpacks to delimit their personal space (Figures 9 and 10);
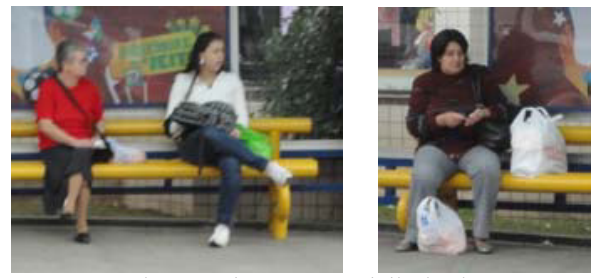

Fig. 9 and 10: Space delimitation

- Exploration: using alternative elements as seats may be perceived by other users as 'breaking the rules' [1]. When people don't find a vacant place to seat in the shelter, they seat on the walls next to the shelter (Figures 11 and 12);
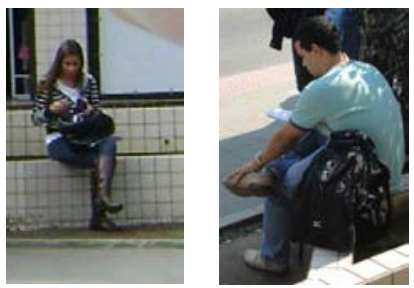

Fig. 11 and 12: Exploration

- Obstruction: it happens when someone occupies much more space than normal, whether to keep personal belongings, or with his/her own presence. Some users' large objects obstruct the shelter's space (Figure 13), and the crowd ob- 
structs the circulation of pedestrians on peak hours (Figure 14).
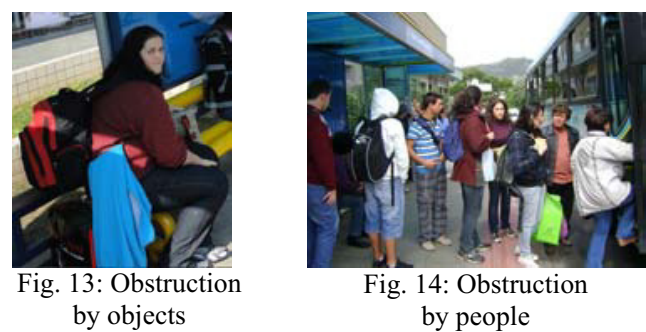

Fig. 14: Obstruction by people

\subsubsection{Proxemics and personal space}

Distances between users vary according to circumstances. The proximity between users is common when the shelter is crowded. When there is more space, people tend to keep more space between them [1].

This variation is evident when the bus arrives. Users move themselves, looking for a personal space that best suits their needs (Figures 15-18).

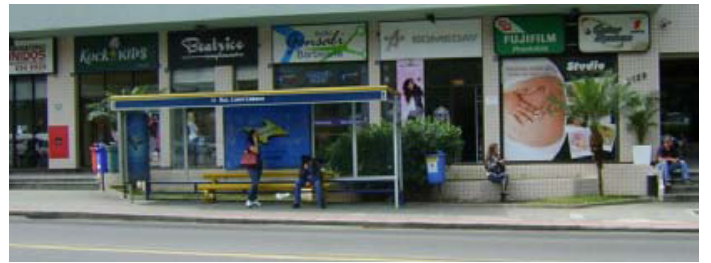

Fig. 15: Few users and a lot of space

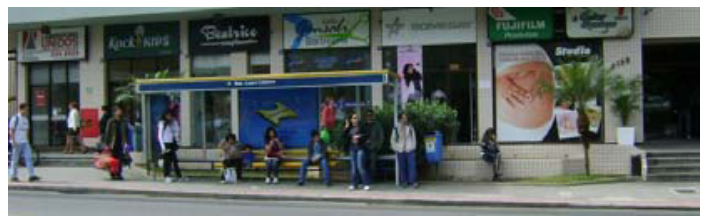

Fig. 16: The distance between users reduces when more of them arrive

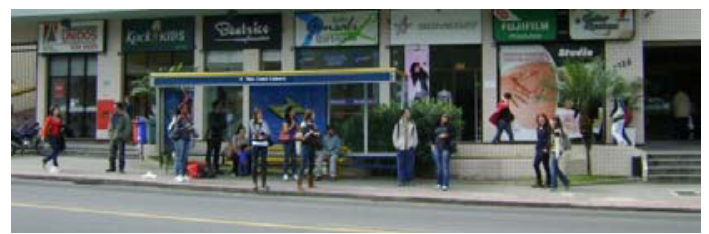

Fig. 17: Users are closer to each other, just before the bus arrives

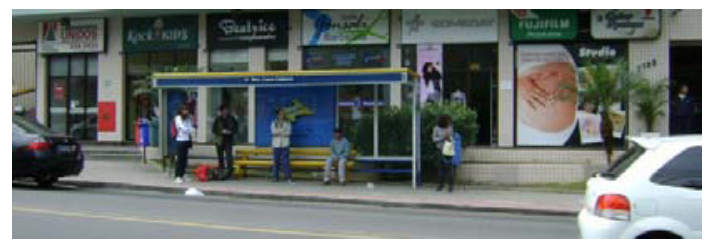

Fig. 18: After the bus departure users switch their positions looking for a personal distance that best suits their needs
Two kinds of relationships between users were identified: interaction and interpersonal:

- Interactions are occasional relationships between strangers. They occur, mostly, due to their simultaneous presence at the same place, doing the same activities [1]. In the shelter, the most common interaction occurred when users stranger to each other started a conversation, probably trying to distract themselves (Figure 19 and 20);

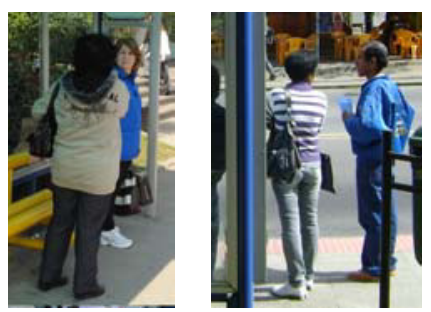

Fig. 19 and 20: Interactions

- The interpersonal relationship happens independently of the place. It occurs between people that already know each other [1]. Interpersonal relationships were observed between friends, couples and other groups that used the shelter (Figure 21 and 22).

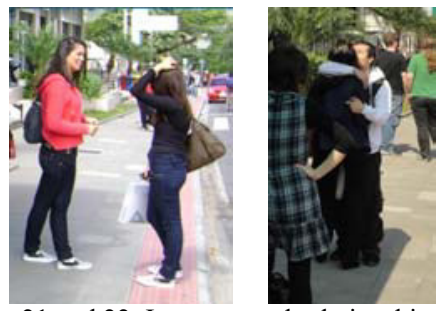

Fig. 21 and 22: Interpersonal relationships

\subsection{Users' perception}

It is possible to infer that shelters do not provide physical comfort, because $62 \%$ of the users think that shelters' dimensions are too small, $83 \%$ think that weather protection is inadequate and $70 \%$ think that the shelter is too hot in the summer.

It is possible to suppose that shelters are not providing psychological comfort either because most of the interviewed users believed that the waiting time in the bus stop was too long, even though it rarely overpasses 10 minutes. Most prefer to wait in the standing position because otherwise they find it difficult to see the bus coming. The visibility is worse for elderly, because they prefer to wait seated. Furthermore, the shelter does not display information about 
bus routes and timetables. For the most part, users don't notice the information displayed in the bus stop (name of the street and number of the shelter), and $96 \%$ of those who know about this information think that it's useless to help understanding the city's transportation system. To overcome the lack of information, $43 \%$ of the users find it on the Internet.

\subsubsection{Constellation of Attributes}

The attributes of an ideal shelter are represented by Figure 23. Physical comfort characteristics were the most desirable ones.

The attributes of current shelters are represented by Figure 24. Physical comfort characteristics were the most criticized.

From the comparison between the constellation of attributes and the remaining results, it is possible to conclude that the shelter is not providing physical comfort. The attributes most frequently mentioned as desirable in an ideal shelter (adequate protection from the weather, comfort of the seats and adequacy of shelter's dimensions) were also the most frequently mentioned as inadequate in current shelters.

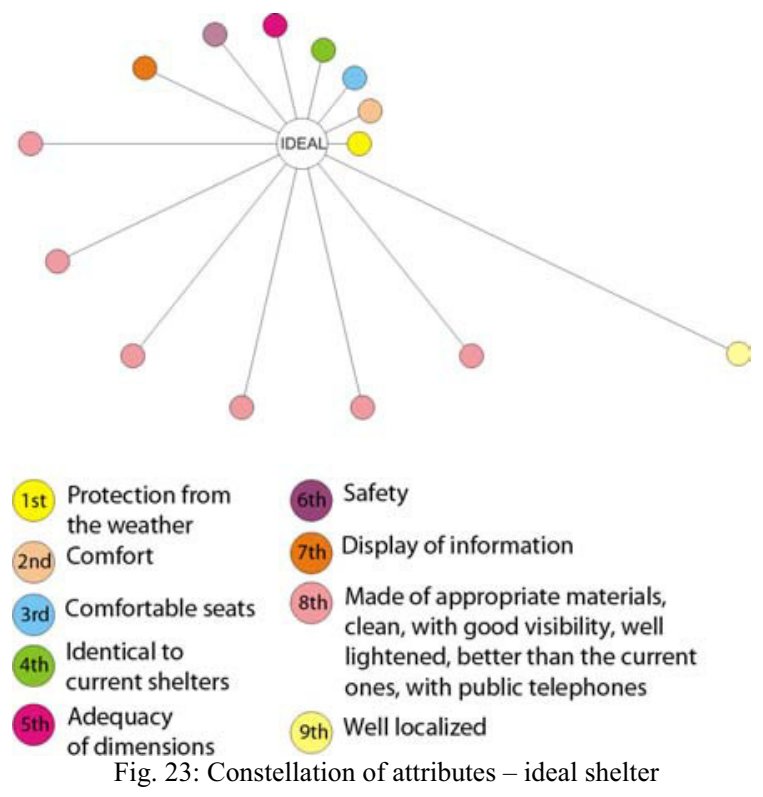

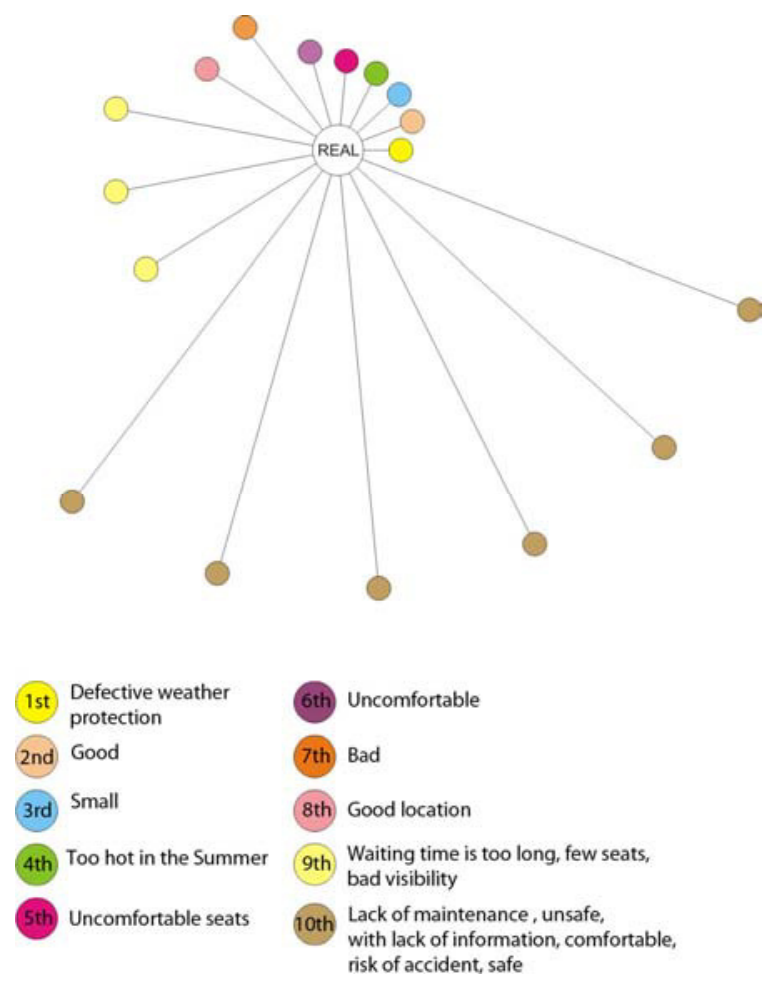

Fig. 24: Constellation of attributes - actual shelter

\section{Recommendations}

In order to improve physical comfort, shelters should provide:

- More protection from weather elements. It is possible to avoid rain drops by increasing the width of the sides protection and by extending all shelters' protections till the floor. These protections must remain transparent, in order to maintain visibility;

- An adequate thermal comfort, especially on the roof; they should be made of proper materials;

- More comfortable seats, designed for users with different heights and made of materials that do not get too much cool in the winter;

- High benches or holders for users to wait in a standing position;

- Adequate dimensions that take into account the number of users. If it's not possible to increase its dimensions, then the redistribution of bus routes is recommended, reducing the relative number of users per shelter.

In order to improve psychological comfort, the shelter must provide a wide view so people can see the buses approaching. This can be achieved by: 
- Creating places for people to wait in a standing position, located in such a way that they do not obstruct the visibility of those who are seated;

- Placing seats obliquely in relation to the street (only possible in larger shelters);

- Reducing circulation conflicts. On larger sidewalks, pedestrian circulation could pass behind the shelter;

The display of information about the transportation system may also improve users' psychological comfort. The shelter could provide:

- An electronic panel, which informs the buses timetables. This panel could also display further information, such as the time and weather conditions;

- An audible information system, which may help elderly and visually impaired people

- Bus timetables and routes;

- City neighborhood maps, highlighting tourist attractions and other landmarks.

\section{Last considerations}

Some characteristics of the shelter are increasing users' fatigue while they're waiting for the bus. The study found that the most relevant causes of discomfort were related to thermal conditions, benches' design, difficulty to see the arrival of the buses and lack of information about the transportation system. The most positive attribute was the easy identification of the shelters by users due to its standard design.
Most of the recommendations made in the previous study [1] were not followed during the current shelter's project, and the new bus stop shelter does not meet the user's needs. If this shelter provided higher levels of physical and psychological comfort, its users would feel less unsatisfied about waiting their time in them.

To repeat this same survey on summer might cause different results related to thermal comfort and to the quality of information about the transportation system, because of the temperature difference between seasons and of the great number of tourists that the city receives during that time of year.

\section{References}

[1] Bins Ely, V.H.M. (1997). Avaliação de fatores determinantes no posicionamento de usuários em abrigos de ônibus a partir do método da grade de atributos. Florianópolis, 1997. Tese (Doutorado em Engenharia de Produção e Sistemas) - Centro Tecnológico, Universidade Federal de Santa Catarina.

[2] Gifford, R. (1987). Environmental Psychology: Principles and pratice. Massachussets: Allyn and Bacon.

[3] Hall, E.T. (1966). The hidden dimension. New York: Doubleday.

[4] Iida, I. (2005). Ergonomia : projeto e produção. São Paulo : Edgar Blücher Ltda.

[5] SOCIEDADE BRASILEIRA DE PEDIATRIA. Semiologia Pediátrica: Valores de referência. Disponível em: http://www.sbp.com.br/img/documentos/valores referencia.pd f. Acesso em julho de 2010 .

[6] Villarouco, V. (2008). Construindo uma metodologia de avaliação ergonômica do ambiente - AVEA. Proceedings of the 15th Brazilian Congress of Ergonomics, Porto Seguro, BA, Brazil.

[7] Zeizel, J. (2006) Inquiry by design: Environmental/ behaviour / neuroscience in architecture, interiors, landscape and planning. New York: W.W. Norton \& Company. 